\title{
Substratos e estacas com e sem folhas no enraizamento de Luehea divaricata Mart.
}

\author{
Substrates and stem cuttings with and without leafs on rooting of Luehea divaricata Mart.
}

\author{
Jardel Pizzatto Pacheco $^{I^{*}}$ Elci Terezinha Henz Franco ${ }^{\mathrm{I}}$
}

\section{RESUMO}

O objetivo deste trabalho foi avaliar a influência do substrato e do tipo de estaca no enraizamento de Luehea divaricata. O experimento foi realizado no Viveiro Florestal da Universidade Federal de Santa Maria (UFSM), no período de dezembro de 2006 a fevereiro de 2007. Foram utilizadas estacas herbáceas (com folha e sem folha), de plantas matrizes com aproximadamente dois anos de idade e diferentes tipos de substrato (turfa, Plantmax ${ }^{\circledR}$, vermiculita, Mecplant ${ }^{\circledR}$ ) em arranjo fatorial $2 \times 4$. O delineamento experimental foi inteiramente casualizado, com cinco unidades experimentais por repetição e 10 repetições por tratamento. As avaliações foram realizadas 60 dias após a implantação do experimento. As variáveis observadas foram sobrevivência, enraizamento, número de raízes, comprimento das raízes, matéria seca das raízes e matéria seca da parte aérea. O tipo de estaca apresentou influência em todas as variáveis estudadas, tendo em vista que 100\% das estacas sem folha morreram antes de enraizar. Estacas cultivadas em Plantmax ${ }^{\circledR}$ apresentaram maior comprimento das raízes quando comparadas ao substrato Mecplant ${ }^{\circledR}$. A utilização dos substratos turfa e Plantmax ${ }^{\circledR}$ permitiu obter maiores valores de matéria seca da parte aérea e matéria seca das raízes. Estacas com um par de folhas cultivadas em Plantmax $^{\circledR}$ são indicadas na estaquia de Luehea divaricata.

Palavras-chave: açoita-cavalo, espécie florestal, propagação vegetativa.

\section{ABSTRACT}

An experiment was carried out to evaluate the influence of substrate and type of stem cuttings on the rooting of Luehea divaricata. The experiment was conducted at a Forest Seedbed at the Federal University of Santa Maria (UFSM), from December 2006 to February 2007. Herbaceous stem cuttings were used (with and without leaf), of plant matrices of approximately two years of age distributed as substrate (peat, Plantmax $^{\circledR}$, vermiculite, Mecplant ${ }^{\circledR}$ ) in factorial $2 \times 4$. The experimental design was completely randomized and consisted of bifactorial combination with five units per repetition and 10 repetitions per treatment. The evaluations have been performed 60 days after the implantation of the experiment. The variables observed were: survival, rooting, number of roots, length of roots and dry mass of the roots and of the aerial part. The type of stem cuttings presented influence for the variables analyzed, considering that $100 \%$ of the stem cuttings without leaf died before rooting. Stem cuttings cultivated in Plantmax ${ }^{\circledR}$ showed higher length of the roots than Mecplant ${ }^{\circledR}$. The use of peat and Plantmax ${ }^{\circledR}$ substrate enabled more values for the dry mass of leaf and roots. Stem cuttings with a pair of leaf grown in Plantmax ${ }^{\circledR}$ are indicated in the vegetative propagation of Luehea divaricata.

Key words: açoita-cavalo, forest species, vegetative propagation.

\section{INTRODUÇÃO}

A produção de móveis em escala industrial vem acompanhada pelo aumento da produção madeireira que, em parte, está condicionada ao melhoramento genético e ao manejo silvicultural (JÚNIOR, 1993). Os elevados padrões de exigência de mercado justificam o emprego de métodos que visam seleção de matrizes adequadas ao uso comercial (PONCE, 1997).

Luehea divaricata, popularmente conhecida como açoita-cavalo, ibitinga e ivantingui é uma árvore da família Tiliaceae com ocorrência do Rio Grande do Sul ao sul da Bahia (LORENZI, 1998). O Estado do Rio Grande do Sul apresenta condições

IPrograma de Pós-graduação de Engenharia Florestal, Universidade Federal de Santa Maria (UFSM), Santa Maria, RS, Brasil.

*Endereço para correspondência: Rua Erly de Almeida Lima, nº 195, apto 302, 97105120. Email: jardelcb@yahoo.com.br. 
edafoclimáticas favoráveis ao cultivo de Luehea divaricata. Árvore típica de solos aluviais, possui madeira com média retratibilidade e baixa resistência mecânica, características que a qualificam para fabricação de móveis vergados e peças torneadas (RIZZINI, 1971; LORENZI, 1998). Além disso, ela pode ser usada na construção civil, sendo, nesse caso, empregada na fabricação de molduras, guarnições e rodapés (REITZ et al., 1988).

A obtenção de matrizes adequadas ao uso comercial é um dos principais obstáculos à propagação dessa espécie. A variabilidade obtida na propagação sexuada dificulta a obtenção de matrizes com características desejáveis, pois, na maioria das vezes, dão origem a indivíduos de fuste irregular e tortuoso. A utilização da estaquia como método de propagação clonal pode evitar esses inconvenientes, pois, além de reduzir o tempo necessário à formação das mudas, permite a fixação das características de interesse (MESEN et al., 1997). Assim baseia-se no princípio de que é possível obter uma nova planta por meio da desdiferenciação dos tecidos da planta matriz (HARTMANN et al., 2002).

O sucesso da propagação por estaquia está, em parte, relacionado à escolha do substrato (COUVILLON, 1988). Conforme definição, devem ser utilizados substratos suficientemente porosos, com boa capacidade de retenção hídrica e drenagem satisfatória (OLIVEIRA et al., 2003). Além disso, devem apresentar boa aeração, baixa resistência ao crescimento radicial e ser isento de patógenos (MOMENTÉ et al., 2002). Sabese, entretanto, que as condições físico-químicas necessárias à formação de raízes adventícias variam entre espécies (VERDONCK et al., 1981). Dessa forma, a determinação de parâmetros referentes à densidade, porosidade, disponibilidade de água e capacidade de troca catiônica (CTC) podem ser úteis para avaliar em quais condições físico-químicas a espécie apresenta maior desenvolvimento (SCHMITZ et al., 2002).

A perda de água por transpiração e a baixa qualidade radicial estão entre as principais causas da morte em estacas herbáceas (DE KLERK et al., 1999; SCHWENGBER et al., 2000). Aretenção foliar pode reduzir a morte das estacas, pois são fontes naturais de carboidrato e auxina (ARAÚJO et al., 1999). A auxina produzida pelas folhas reduz o tempo necessário ao enraizamento e, conseqüentemente, a morte das estacas por déficit hídrico (DIAS et al., 1999). Além disso, a síntese de compostos fenólicos via foliar pode estar envolvida no enraizamento adventício das estacas, tendo em vista sua participação como cofator de enraizamento (HESS, 1968). Por outro lado, são facilmente oxidados e os produtos desta oxidação são fitotóxicos ao desenvolvimento da estaca (FACHINELLO et al., 1995).
Considerando o potencial desta espécie como fonte de matéria-prima para indústrias moveleiras e a necessidade de inserir espécies nativas neste segmento, o objetivo desse trabalho foi avaliar a influência de diferentes substratos em estacas de Luehea divaricata.

\section{MATERIAL E MÉTODOS}

O experimento foi realizado no Viveiro Florestal do Departamento de Engenharia Florestal da Universidade Federal de Santa Maria (UFSM), no período de dezembro de 2006 a fevereiro de 2007. Ramos herbáceos foram coletados de 10 plantas matrizes, com aproximadamente dois anos de idade, cultivadas em casa de vegetação da Universidade Federal de Santa Maria. Foram preparadas 400 estacas herbáceas basais com 8,0 cm de comprimento e diâmetro médio de 4,0 $\mathrm{mm}$, sendo cortadas em bisel, abaixo do nó inferior, e horizontalmente acima do nó superior. Foram confeccionados dois tipos de estacas: com um par de folhas, reduzidas a um terço da área foliar, e sem folhas. O estaqueamento foi realizado em tubetes plásticos cônicos, com dimensões de 28 x 12 $\mathrm{x} 125 \mathrm{~mm}$.

Os tratamentos consistiram na combinação entre dois tipos de estaca (com e sem folha) e quatro substratos (vermiculita, Mecplant ${ }^{\circledR}$, Plantmax ${ }^{\circledR}$ e turfa). Os substratos foram submetidos à análise física, conforme metodologia descrita por SMITH \& POKORNY (1977), no laboratório de análises físicas do Departamento de Solos da Universidade Federal de Santa Maria (UFSM). A análise química foi realizada no Laboratório de Análise de Solos da UFSM, de acordo com a metodologia descrita por TEDESCO et al. (1995). As medidas relativas ao comprimento das raízes foram realizadas por meio da média, em centímetros, das raízes primárias obtidas. Do mesmo modo, foram consideradas apenas as raízes primárias para a variável número das raízes. Para determinação da matéria seca, em miligramas, foram secas as raízes e a parte aérea em estufa de ventilação forçada a $50^{\circ} \mathrm{C}$ até ser atingida a constância de massa.

O delineamento experimental foi inteiramente casualizado, em arranjo fatorial $2 x 4$, consistindo de cinco unidades experimentais por repetição e 10 repetições por tratamento. A condução do experimento foi realizada sob câmara de microaspersão com 22 irrigações diárias e intervalo de 30 minutos, tendo cada uma duração de dois minutos. Os dados em porcentagem foram transformados pela equação arco seno v(x /100) e os dados de contagem pela equação $\mathrm{v}(\mathrm{x}+1)$, seguindo distribuição normal. Posteriormente, foram submetidos à análise de variância pelo 
procedimento General Linear Model (GLM), incluindo no modelo os efeitos do substrato (S), da folha (F) e da interação $S^{*} \mathrm{~F}$. As diferenças entre as médias foram comparadas pelo Teste de Tukey a 5\% de probabilidade. As análises estatísticas foram realizadas através do software MINITAB (MACKENZIE \& GOLDMAN, 1999).

\section{RESULTADOS E DISCUSSÃO}

Os valores das variáveis sobrevivência, enraizamento, número de raízes, comprimento das raízes, matéria seca das raízes e matéria seca da parte aérea são apresentados na tabela 1 . A presença da folha apresentou influência em todas as variáveis estudadas. Não houve interação entre folha e substrato para enraizamento e número de raízes. As variáveis comprimento das raízes, matéria seca das raízes e matéria seca da parte aérea foram influenciadas pela interação folha e substrato (Tabela 2). Estacas com folhas cultivadas em Plantmax ${ }^{\circledR}$ apresentaram maior matéria seca das raízes $(57,7 \mathrm{mg})$ e da parte aérea (73,4mg). Embora a análise estatística tenha indicado interação, estes resultados devem ser analisados com certo critério, tendo em vista que 100\% das estacas sem folhas morreram antes mesmo de enraizar. Portanto, a interação observada neste experimento reflete, simplesmente, o efeito do substrato sobre as variáveis comprimento das raízes, matéria seca das raízes e matéria seca da parte aérea.

De qualquer forma, a permanência da folha em estacas de Luehea divaricata permitiu obter aproximadamente $28,1 \%$ das estacas enraizadas, contrastando com a ausência de enraizamento em estacas sem folha. Os resultados demonstram que a presença da folha em estacas herbáceas de Luehea divaricata é fator limitante ao enraizamento adventício. É provável que as diferenças entre estacas com e sem folhas sejam, em parte, atribuídas a síntese de auxina e a fotoassimilados pelas folhas. Do ponto de vista teórico, a auxina sintetizada via foliar desloca-se em direção basípeta, onde ocorre diferenciação celular em primórdios radiciais (JANICK, 1966). Neste estudo, a antecipação do enraizamento em estacas com folhas confirma a hipótese de que a retenção foliar favorece o enraizamento adventício e, conseqüentemente, a sobrevivência das estacas (HARTMANN et al., 2002). Por outro lado, a quantidade de auxina endógena em estacas sem folha foi insuficiente para formação radicial. Dessa forma, não houve compensação da água perdida pelos tecidos, tendo em vista a ausência de primórdios radiciais nestas estacas.

Embora o enraizamento seja função de vários fatores, é provável que a retenção foliar em estacas de Luehea divaricata tenha aumentado a mobilização de fotoassimilados aos primórdios radiciais. A síntese de fotoassimilados pode ser particularmente importante, pois é responsável pela manutenção das atividades metabólicas, sendo fonte de energia e carbono estrutural ao enraizamento (LIONAKIS, 1984). Os resultados obtidos neste experimento são embasados por outros estudos, que verificaram relação entre retenção foliar e enraizamento adventício (MAYER \& PEREIRA, 2003). Dessa forma, sabendo que as folhas são locais de síntese de auxina e carboidratos, seria de se esperar que a retenção foliar

Tabela 1 - Valores médios para sobrevivência, enraizamento, número de raízes, comprimento das raízes, matéria seca das raízes e matéria seca da parte aérea em estacas de Luehea divaricata com e sem folhas cultivadas em diferentes substratos. Santa Maria, RS, 2005.

\begin{tabular}{|c|c|c|c|c|c|c|}
\hline \multirow[t]{2}{*}{ Tratamentos } & \multicolumn{2}{|c|}{-----------------Estaca----------------- } & \multicolumn{3}{|c|}{-------------------------Raízes------------------------ } & \multirow{2}{*}{$\begin{array}{c}\text { Folhas } \\
\text { Matéria seca mg }\end{array}$} \\
\hline & Enraizamento \% & Sobrevivência \% & Número & Comprimento cm & Matéria seca mg & \\
\hline \multicolumn{7}{|l|}{ Folha } \\
\hline Presença & $28,19^{\mathrm{a}}$ & $28,19^{\mathrm{a}}$ & $1,80^{\mathrm{a}}$ & $6,21^{\mathrm{a}}$ & $42,0^{\mathrm{a}}$ & $46,8^{\mathrm{a}}$ \\
\hline Ausência & $0^{\mathrm{b}}$ & $0^{\mathrm{b}}$ & $0^{\mathrm{b}}$ & $0^{\mathrm{b}}$ & $0^{\mathrm{b}}$ & $0^{\mathrm{b}}$ \\
\hline \multicolumn{7}{|l|}{ Substrato } \\
\hline Turfa & $19,3^{\mathrm{a}}$ & $19,3^{\mathrm{a}}$ & $1,41^{\mathrm{a}}$ & $5,10^{\mathrm{a}}$ & $34,9^{\mathrm{ab}}$ & $36,0^{\mathrm{ab}}$ \\
\hline Plantmax $^{\circledR}$ & $16,0^{\mathrm{a}}$ & $16,0^{\mathrm{a}}$ & $1,40^{\mathrm{a}}$ & $4,57^{\mathrm{ab}}$ & $39,1^{\mathrm{a}}$ & $49,7^{\mathrm{a}}$ \\
\hline Vermiculita & $11,6^{\mathrm{a}}$ & $11,6^{\mathrm{a}}$ & $0,85^{\mathrm{a}}$ & $3,24^{\mathrm{abc}}$ & $12,3^{\mathrm{c}}$ & $11,8^{\mathrm{c}}$ \\
\hline Mecplant $^{\circledR}$ & $9,24^{\mathrm{a}}$ & $9,24^{\mathrm{a}}$ & $0,74^{\mathrm{a}}$ & $2,24^{\mathrm{c}}$ & $14,5^{\mathrm{bc}}$ & $13,7^{\mathrm{bc}}$ \\
\hline $\mathrm{dpr}^{1}$ & 13,9 & 13,9 & 0,78 & 2,26 & 1,7 & 29,9 \\
\hline
\end{tabular}

${ }^{1}$ Desvio padrão residual; letras diferentes na mesma coluna diferem pelo teste de Tukey a 5\% de probabilidade de erro.

Ciência Rural, v.38, n.7, out, 2008. 
Tabela 2 - Interação entre tipo de estaca (com e sem folha) e substrato (turfa, Plantmax ${ }^{\circledR}$, vermiculita, Mecplant ${ }^{\circledR}$ ) para as variáveis comprimento das raízes, matéria seca das raízes e matéria seca da parte aérea em estacas de Luehea divaricata. Santa Maria, RS, 2005.

\begin{tabular}{|c|c|c|c|}
\hline \multirow{2}{*}{ Folha x Substrato } & \multicolumn{2}{|c|}{ 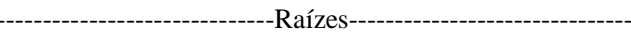 } & Folhas \\
\hline & Comprimento cm & Matéria seca mg & Matéria seca mg \\
\hline Ausência x Turfa & $0,00^{\mathrm{e}}$ & $0,00^{\mathrm{C}}$ & $0,00^{\mathrm{c}}$ \\
\hline Presença x Turfa & $7,66^{\mathrm{a}}$ & $52,4^{\mathrm{ab}}$ & $54,0^{\mathrm{ab}}$ \\
\hline Ausência x Plantmax ${ }^{\circledR}$ & $0,00^{\mathrm{e}}$ & $0,00^{\mathrm{c}}$ & $0,00^{\mathrm{c}}$ \\
\hline Presença x Plantmax ${ }^{\circledR}$ & $6,74^{\mathrm{ab}}$ & $57,7^{\mathrm{a}}$ & $73,4^{\mathrm{a}}$ \\
\hline Ausência x Vermiculita & $0,00^{\mathrm{e}}$ & $0,00^{\mathrm{c}}$ & $0,00^{\mathrm{c}}$ \\
\hline Presença x Vermiculita & $5,27^{\mathrm{bc}}$ & $20,0^{\mathrm{ac}}$ & $19,1^{\mathrm{c}}$ \\
\hline Ausência x Mecplant ${ }^{\circledR}$ & $0,00^{\mathrm{e}}$ & $0,00^{\mathrm{c}}$ & $0,00^{\mathrm{c}}$ \\
\hline Presença x Mecplant $^{\circledR}$ & $4,10^{\text {bcd }}$ & $26,7^{\mathrm{abc}}$ & $25,2^{\mathrm{bc}}$ \\
\hline $\mathrm{dpr}^{1}$ & 2,26 & 21,7 & 29,9 \\
\hline
\end{tabular}

${ }^{1}$ Desvio padrão residual; letras diferentes na mesma coluna diferem pelo teste de Tukey a 5\% de probabilidade de erro.

favorecesse a sobrevivência e a formação radicial. Além disso, é provável que o enraizamento e a sobrevivência das estacas com folha estejam relacionados à síntese de compostos fenólicos pela parte aérea. Estudos indicam que certos compostos fenólicos, como é o caso do ácido caféico, catecol e clorogênico, interagem com as auxinas, induzindo a iniciação das raízes.

Por outro lado, para que essas condições sejam satisfeitas, é indispensável controlar as condições de temperatura e umidade onde permanecem as estacas (ANDERSEN, 1986). Sabe-se que a queda das folhas, seja por excesso de temperatura ou pela baixa umidade relativa, pode limitar a produção de mudas clonais. Os resultados de enraizamento e sobrevivência obtidos neste estudo estão abaixo dos níveis aceitáveis em programas de propagação clonal, tendo em vista as altas temperaturas $\left(35^{\circ} \mathrm{C}\right)$ durante o período experimental. Entretanto, esses resultados sugerem que, desde que sejam mantidas condições favoráveis à retenção foliar, pode-se viabilizar a propagação clonal em Luehea divaricata.

Os resultados referentes à análise físicoquímica dos substratos são apresentados na tabela 3 . O substrato não apresentou influência sobre o enraizamento e o número de raízes. As variáveis comprimento das raízes, matéria seca das raízes e matéria seca da parte aérea foram influenciadas pelo substrato. Estacas cultivadas em turfa e Plantmax ${ }^{\circledR}$ apresentaram maior comprimento radicial, aproximadamente 127 e 104\% superior em relação àquelas cultivadas em Mecplant ${ }^{\circledR}$. Relacionando esses resultados com as propriedades físicas dos substratos podemos identificar alguns parâmetros que influenciaram o comprimento radicial. Os maiores valores de comprimento radicial coincidiram com a

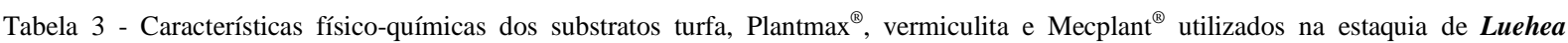
divaricata. Santa Maria, RS, 2005.

\begin{tabular}{|c|c|c|c|c|c|c|c|}
\hline Substrato & Umidade $\mathrm{cm}^{3} \mathrm{~cm}^{-3}$ & \multicolumn{2}{|c|}{ Densidade $\mathrm{g} \mathrm{cm}^{-3}$} & Porosidade $\mathrm{cm}^{3} \mathrm{~cm}^{-3}$ & \multicolumn{2}{|c|}{ Água $\mathrm{cm}^{3} \mathrm{~cm}^{-3}$} & Espaço $\mathrm{cm}^{3} \mathrm{~cm}^{-3}$ \\
\hline & $\mathrm{STR}^{1}$ & STR & Seco & Total & $\mathrm{DPN}^{2}$ & $\mathrm{RMN}^{3}$ & Aéreo \\
\hline Turfa & 0,78 & 0,24 & 0,27 & 0,78 & 0,27 & 0,35 & 0,15 \\
\hline Plantmax $^{\circledR}$ & 0,76 & 0,31 & 0,36 & 0,76 & 0,30 & 0,31 & 0,13 \\
\hline Vermiculita & 0,79 & - & 0,10 & 0,79 & 0,08 & 0,40 & 0,31 \\
\hline Mecplant $^{\circledR}$ & 0.77 & 0,17 & 0,20 & 0,77 & 0,14 & 0,26 & 0,36 \\
\hline \multirow{2}{*}{ Substrato } & $\% \mathrm{MO}^{4}$ & $\mathrm{P}$ & K & $\mathrm{pH}$ & $\mathrm{Ca}$ & $\mathrm{Mg}$ & $\mathrm{CTC}^{5}$ \\
\hline & $\mathrm{m} \mathrm{v}^{-1}$ & \multicolumn{2}{|c|}{----'mg dm ${ }^{-3}$-------- } & $1: 1$ & \multicolumn{3}{|c|}{----------------Cmol $\mathrm{Cm}_{\mathrm{C}} \mathrm{dm}^{-3}$--------------- } \\
\hline Turfa & 10,5 & 75 & 108 & 5,2 & 33,7 & 6,2 & 83,5 \\
\hline Plantmax $^{\circledR}$ & 15,9 & 76 & 800 & 4,7 & 19,2 & 6,7 & 71,2 \\
\hline Vermiculita & 0,2 & 2,2 & 80 & 6,7 & 1,23 & 6,2 & 50,9 \\
\hline Mecplant ${ }^{\circledR}$ & 20,7 & 74 & 440 & 3,8 & 11,5 & 5,9 & 61,8 \\
\hline
\end{tabular}

${ }^{1}$ Saturada, ${ }^{2}$ disponível, ${ }^{3}$ remanescente, ${ }^{4}$ matéria orgânica, ${ }^{5}$ capacidade de troca catiônica. 
maior densidade, a disponibilidade de água e o menor espaço aéreo, características encontradas nos substratos turfa e Plantmax ${ }^{\circledR}$. Por outro lado, substratos com menor densidade, disponibilidade de água e maior espaço aéreo, como é o caso da vermiculita e do Mecplant $^{\circledR}$, apresentaram menor comprimento radicial. As condições ideais ao crescimento radicial variam entre espécies, entretanto, é consenso que substratos com alta densidade e, conseqüentemente, baixa porosidade dificultam o crescimento radicial (VERDONCK et al., 1981). Entretanto, os valores de comprimento radicial foram maiores em substratos com maior densidade aparente. A hipótese explicativa para esse resultado pode estar relacionada às densidades dos substratos vermiculita $\left(0,10 \mathrm{~g} \mathrm{~cm}^{-3}\right)$ e Mecplant ${ }^{\circledR}$ $\left(0,20 \mathrm{~g} \mathrm{~cm}^{-3}\right)$, consideradas abaixo dos valores ideais $(0,4$ $\left.-0,5 \mathrm{~g} \mathrm{~cm}^{-3}\right)$.

É provável que a disponibilidade de água (DA) tenha influenciado o comprimento radicial em estacas de Luehea divaricata. Estudos indicam que a DA recomendada situa-se entre 0,24 e $0,40 \mathrm{~m}^{3}$ $\mathrm{m}^{-3}$,entretanto, podem existir variações conforme as dimensões do recipiente utilizado (DE BOODT \& VERDONCK, 1972). Neste experimento, os únicos substratos a apresentar DA dentro destes limites foram a turfa $\left(0,27 \mathrm{~cm}^{3} \mathrm{~cm}^{-3}\right)$ e o Plantmax ${ }^{\circledR}\left(0,30 \mathrm{~cm}^{3} \mathrm{~cm}^{-3}\right)$. A adequação aos limites considerados ideais permitiu obter maiores valores de comprimento radicial em turfa $(5,10 \mathrm{~cm})$ e Plantmax ${ }^{\circledR}(4,57 \mathrm{~cm})$, respectivamente. Por outro lado, os substratos Mecplant ${ }^{\circledR}$ e vermiculita apresentaram DA abaixo dos valores recomendados. De qualquer modo, o parâmetro DA mostrou ser fator de restrição no crescimento radicial em Luehea divaricata, tendo em vista os resultados anteriormente descritos.

O comprimento radicial também esteve relacionado ao espaço de aeração (EA) que, em condições de saturação hídrica, corresponde à fração do substrato preenchido por ar (VALERO, 2006). A relação entre desenvolvimento radicial e espaço de aeração pode estar vinculada ao suprimento adequado de oxigênio ao crescimento radicial (SOFFER \& BURGER, 1988). Do ponto de vista teórico, o substrato deve ser suficientemente poroso para realização das trocas gasosas, manutenção do crescimento radicial e da atividade microbiana (PICOLOTTO et al., 2007). Embora todos os substratos estejam dentro dos limites recomendados $\left(0,10 \mathrm{~m}^{3} \mathrm{~m}^{-3}-0,40 \mathrm{~m}^{3} \mathrm{~m}^{-3}\right)$, foram obtidas raízes mais longas em turfa $\left(0,15 \mathrm{~m}^{3} \mathrm{~m}^{-3}\right)$ e Plantmax ${ }^{\circledR}$ $\left(0,13 \mathrm{~m}^{3} \mathrm{~m}^{-3}\right)$, ambos com menores valores para espaço de aeração. Outros experimentos revelam diferentes respostas de crescimento radicial em função deste parâmetro. Estudos realizados com Myrciaria jaboticaba obtiveram maior comprimento radicial em substratos com grande espaço de aeração (PIO et al., 2005). Por outro lado, estacas de Chamaecyparis lawsoniana apresentaram maior comprimento radicial quando cultivadas em substrato com pequeno espaço de aeração (STUMPF et al., 1999). Como se pôde observar, as condições ideais ao crescimento radicial variam conforme a espécie propagada, confirmando a hipótese de que não existe substrato universal ao enraizamento.

Houve efeito do substrato sobre a variável matéria seca das raízes (MSR). Estacas cultivadas em Plantmax $^{\circledR}(39,1 \mathrm{mg})$ apresentaram MSR superior à vermiculita (12,3mg) e ao Mecplant ${ }^{\circledR}(14,5 \mathrm{mg})$, entretanto, não diferiram em relação às cultivadas em turfa (34,9mg). Provavelmente, os resultados para MSR estejam relacionados ao comprimento das raízes obtido nesses substratos. Estacas cultivadas em turfa e Plantmax $^{\circledR}$, ambas com maiores valores de CR, também apresentaram maior MSR, confirmando a hipótese de que a MSR é, em parte, influenciada pelo comprimento das raízes. Por outro lado, não houve relação entre CR e MSR em estacas cultivadas nos substratos vermiculita e Mecplant, tendo em vista que o menor CR observado em Mecplant ${ }^{\circledR}$ não correspondeu ao menor valor da matéria seca das raízes. Nesse caso, a superioridade do substrato Mecplant ${ }^{\circledR}$ pode ser explicada pelas suas características químicas. A análise química dos substratos indicou variações significativas nos teores de matéria orgânica, cálcio, fósforo e potássio entre vermiculita e Mecplant ${ }^{\circledR}$. Dessa forma, é provável que os maiores valores de MSR em Mecplant ${ }^{\circledR}$ estejam relacionados à disponibilidade nutricional desse substrato. Considerando que a vermiculita é praticamente inerte, seria de se esperar que estacas cultivadas nesse substrato apresentassem menor desenvolvimento de biomassa radicial.

O substrato influenciou a variável matéria seca da parte aérea seca (MSA). Estacas cultivadas em Plantmax $^{\circledR}(49,7 \mathrm{mg})$ apresentaram MSA superior à vermiculita $(11,8 \mathrm{mg})$ e ao Mecplant ${ }^{\circledR}(13,7 \mathrm{mg})$, entretanto, não diferiram em relação às cultivadas em turfa (36,0mg). Houve correlação entre as variáveis matéria seca da parte aérea e matéria seca das raízes. Estacas com maiores valores de MSR, como é o caso das cultivadas em turfa e Plantmax ${ }^{\circledR}$, apresentaram maior desenvolvimento foliar.

Em mudas clonais, a produção de biomassa foliar pode ser explicada pela composição do substrato, qualidade radicial e tipo de estaca. Considerando a homogeneidade das estacas, é provável que as diferenças de MSA sejam função da qualidade radicial e composição química dos substratos. Estacas

Ciência Rural, v.38, n.7, out, 2008. 
cultivadas em turfa e Plantmax ${ }^{\circledR}$, ambos com maior capacidade de troca catiônica (CTC) e teor de cálcio (Ca), apresentaram maiores valores de matéria seca da parte aérea. Estudos indicam que a disponibilidade de cálcio aumenta a estabilidade da membrana, podendo ainda estar envolvido com atividades de divisão celular e desenvolvimento foliar (NATALE et al., 2005). A capacidade de troca catiônica também pode ser um parâmetro confiável para justificar as diferenças de MSA, tendo em vista que grande parte dos cátions existentes nos substratos são nutrientes (CARNEIRO,1995). Dessa forma, é provável que os valores de CTC observados neste experimento estejam relacionados à fertilidade dos substratos.

A qualidade radicial pode ser particularmente importante nos valores de MSA, uma vez que a manutenção da biomassa depende do suprimento de água e nutrientes pelas raízes (HARTMANN et al., 2002). Neste estudo, é provável que a absorção de nutrientes tenha sido maior nas estacas cultivadas em turfa e Plantmax $^{\circledR}$, comportamento que, provavelmente, determinou maiores valores de matéria seca da parte aérea. De qualquer forma, os resultados sugerem relação entre desenvolvimento radicial e foliar em Luehea divaricata.

\section{CONCLUSÕES}

Estacas de Luehea divaricata cultivadas em turfa e Plantmax ${ }^{\circledR}$ apresentam maiores valores de comprimento das raízes, matéria seca das raízes e matéria seca da parte aérea, entretanto, não diferem em relação ao enraizamento e número de raízes. A permanência da folha apresentou influência em todas as variáveis analisadas, tendo em vista que $100 \%$ das estacas sem folha morreram antes mesmo de enraizar.

\section{REFERÊNCIAS}

ANDERSEN, A.S. Enviromental influences on adventitious rooting in cuttings of now-woody species. In: JACKSON, M.B. New root formation in plants and cuttings. London: $M$. Nijhoff, 1986. p.223-254.

ARAÚJO, P.S.R. et al. Enraizamento de estacas de limeira ácida coletadas em diferentes posições na árvore. Scientia Agrícola, v.56, p.357-361, 1999.

CARNEIRO, J.G.A. Produção e controle de qualidade de mudas florestais. Curitiba: UFPR/FUPEF, 1995. 451p.

COUVILLON, G.A. Rooting responses to different treatments. Acta Horticulturae, v.227, p.187-196, 1988.

DE BOODT, M.; VERDONCK, O. The physical properties of the substrates in horticulture. Acta Horticulturae, v.26, p.3744, 1972.
DE KLERK, G.J. et al. Review the formation of adventitious roots: New concepts, new possibilities. In Vitro Cellular \& Developmental Biology - Plant, v.35, p.189-199, 1999.

DIAS, R.M.S.L. et al. Enraizamento de estacas de diferentes diâmetros em Platanus acerifolia (Aiton) Willdenow. Ciência Florestal, v.9, p.127-136, 1999.

FACHINELLO, J.C. et al. Propagação de plantas frutíferas de clima temperado. Pelotas: UFPel, 1995. 178p.

HARTMANN, H.T. et al. Plant propagation: principles and practices. New Jersey: Prentice Hall, 2002. 880p.

HESS, C.E. Internal and external factors regulating root iniciation. In: WHITTINGTON, W.J. Root growth. London: Butterworth, 1968. p.42-53.

JANICK, J.A. A ciência da horticultura. Rio de Janeiro: Freitas Bastos, 1966. 485p.

JÚNIOR, F.G.D.S. Utilização múltipla da madeira de Pinus caribaea var. hondurensis para produção de celulose Kraft. Série Técnica IPEF, v.9, p.56-62, 1993.

LIONAKIS, S.M. Anatomy of root initiation in stem cuttings of Kiwifruit plant (Actinidia chinensis P.). Fruit, v.39, p.207210, 1984

LORENZI, H. Manual de identificação e cultivo de plantas arbóreas nativas do Brasil. Nova Odessa: Plantarum, 1998. 352p.

MACKENZIE, J.; GOLDMAN, R.N. The student edition of Minitab for windows manual: release 12. Belmont: Addison-Wesley Longman, 1999. 592p.

MAYER, N.A.; PEREIRA, F.M. Enraizamento de estacas herbáceas de quatro clones de umezeiro (Prunus mume Sieb. et Zucc.) durante o inverno ameno, em Jaboticabal-SP. Revista Brasileira de Fruticultura, v.25, p.505-507, 2003.

MESEN, F. et al. Vegetative propagation of Cordia alliodora (Ruiz \& Pavon) Oken: the effects of IBA concentration, propagation medium and cutting origin. Forest Ecology and Management, v.92, p.45-54, 1997.

MOMENTÉ, V.G. et al. Propagação vegetativa por estaquia de mentrasto em diferentes substratos. Revista Ciência Agronômica, v.33, p.5-12, 2002.

NATALE, W. et al. Alterações anatômicas induzidas pelo cálcio na parede celular de frutos de goiabeira. Pesquisa Agropecuária Brasileira, v.40, p.1239-1242, 2005.

OLIVEIRA, A.F.D. et al. Enraizamento de estacas semilenhosas de oliveira sob efeito de diferentes épocas, substratos e concentrações de ácido indolbutírico. Ciência Agrotécnica, v.27, p.117-125, 2003.

PICOLOTTO, L. et al. Diferentes misturas de substratos na formação de mudas de pessegueiro, em embalagem. Scientia Agrária, v.8, p.119-125, 2007.

PIO, R. et al. Substratos na produção de mudas de jabuticaba. Revista Brasileira de Agrociência, v.11, p.425-427, 2005. 
PONCE, R.H. Eucalipto: uso alternativo da madeira. Informe agropecuário, v.18, p.52-57, 1997.

REITZ, R. et al. Projeto madeira do Rio Grande do Sul. Porto Alegre: Corag, 1988. 525p.

RIZZINI, C.T. Árvores e madeiras úteis do Brasil - Manual de dendrologia brasileira. São Paulo: Edgard Blücher/USP, 1971. 294p.

SCHMITZ, J.A.K. et al. Propriedades químicas e físicas de substratos de origem mineral e orgânica para o cultivo de mudas em recipientes. Ciência Rural, v.32, p.937-944, 2002.

SCHWENGBER, J.E. et al. Efeito do sombreamento da planta matriz e do PVP no enraizamento de estacas de ramos de araçazeiro (Psidium cattleyanum Sabine). Revista Brasileira de Agrociência, v.6, p.30-34, 2000.

SMITH, R.C.; POKORNY, F. A physical characterization of some potting substrates in commercial nurseries. [S.l.: s.n.], 1977. 8p.
SOFFER, H.; BURGER, D.W. Studies on plant propagation using the aero-hydroponic method. Acta Horticulturae, v.230, p.261-269, 1988.

STUMPF, E.R.T. et al. Enraizamento de estacas de Chamaecyparis lawsoniana Parl. em cinco substratos com uso de ácido indolbutírico. Ciência Rural, v.29, p.207-211, 1999.

TEDESCO, J.M. et al. Análise de solo, plantas e outros materiais. Porto Alegre: Universidade Federal do Rio Grande do Sul, 1995. 174p.

VALERO, R.M.M. Uso da técnica da “TDR” na estimativa da umidade e condutividade elétrica em substratos orgânicos. 2006. Dissertação (Mestrado em Engenharia Agrícola)- Curso de Pós-graduação em Agronomia, Universidade Estadual de Campinas.

VERDONCK, O. et al. The influence of the substrate to plant growth. Acta Horticulturae, v.126, p.251-258, 1981. 